\title{
A CONCEPTUAL FRAMEWORK ON FUTURISTIC STUDIES
}

\author{
Ms. Sushma Rani \\ Senior Research Fellow, (UGC-SRF), Department of Education, Banasthali University, \\ Jaipur, Rajasthan, India
}

\section{ABSTRACT}

In early days the main emphases were on the cognitive aspects of learning and traditional instructions of teaching in the classroom using outdated and conventional techniques. But today in this world of constant innovations and discoveries, scientists and gadget-experts are continuously searching for one or the two technological devices a day. Nodoubt technology has made our life much easier and better in many aspects.

In developed countries, technology facilitates and helps students and teacher to learn things in more effective ways. But in the country like India, the development in technology is not upto that mark. We still are moving towards the path of progress. Thus, this paper will best describes about the conceptual framework regarding futuristic studies related to future technologies such as M-Learning, E-Learning, , $i$ Pod, I-Pad self-efficacy learning, Virtual Learning Environment (VLE) etc. In this paper investigator highlighted some of the studies related to trends in futurology and innovations that could prove an important aspect of education technology.

\section{Keywords:}

Innovations, Technological Revolutions, Futurology, Futuristic Studies, Education Technology.

\section{INTRODUCTION}

In this fast innovative and technological era, Information and Communication Technology (ICT) plays an important role in developing competencies of thinking, learning, relating to others, participating and contributing. The learning experiences emphasizes that how changes in communication technology create opportunities and challenges for communities and people living across the globe; as the classrooms are equipped with DVD players, laptop, computers, music players, T.V's, smart phones within built applications such as camera, GPS, multimedia scanner, Bluetooth technology and data storage all in one place and can be used to access the technology anywhere, anyplace.

But today most of the educational institutions are offering latest tools, devices and technologies such as internet, W-Fi connectivity, audio-video conferencing, social networking, online digital libraries, video gaming and simulation devices, learning through whiteboard devices, digital pen, e-book readers etc. are used to impart knowledge to the students though modernity devices and instructive tools. By examining certain changes in communication technology, students gain understanding about how the global community is "contracting". Now the students will be able to communicate over long distances more quickly than they ever could in the past. Through talking to the people in the various parts of the world, students can develop an understanding about how people view the effects of these changes differently. The concept of futuristic technology will DOI : $10.5121 /$ mlaij.2016.3102 
provide an opportunity for the students, teachers, and various stakeholders to cope up with the global challenges, issues and concerns and how to participate in the global community via communication technology.

\section{TRENDS RELATED TO FUTURISTIC STUDY}

McMillan and Schaumacher (1993); "Research advances knowledge and improve practice. Research provides a better source for knowledge and decision making than personal experiences, beliefs, tradition, logic, or institution alone. Bill gates suggested that the changes that have been occurred in the past or history were quite bigger than the changes or revolutions going to be occurred in the coming next 10 years. Bill gates: Chief Software Architect \& Chairman, Microsoft Cooperation, US, 1999 revealed that the new global changes in the gorm of global economy, technological era, knowledge information all that have occurred through the Globalization and technology. Also the statements from World Bank, 1998, quoted as ICT as a revolutionary medicine that has improved the quality and potential of education resulting in maximum access to knowledge for enhancing unprecedented growth for educational enhancements. The new educational policies executed the enormous opportunities for both the powerful and the poor. Thus, the one who earlier lived in the poor environment has now chance to enjoy the sense of binding together through the use of new communication technologies.

Thus, there is a lot of scope of Futuristic research related to E-learning, ICT in teaching-learning process, evaluation, administration, educational policy issues, content and curriculum, impact of ICT on learning and achievement, ICT as an object, ICT as an assisting tool and soon.

\section{RATIONALE OF THE STUDY}

Education is a relatively new branch of knowledge originating the UK and the USA at about the end of the last century. But now in this current era the growth of education is spreading throughout the world at a rapid rate. In India the importance of educational research has been recognized rather late. Research in education is more or less a post-independence feature with us. The scientists and researches all are involving in different fields related to futuristic trends. In the present system, however new literacies have emerged in association with technology. Gilster (1997) suggested that the ability to gather information, knowledge and seek further help, as digital literacy, whereas Burniske, 2000 talked about the global literacy as the potential to read, interpret, execute, implement, message from global perspective. The various other literacies included are communication literacy, technology literacy, information and visual literacy. (Smodin and Lacoless, 2013). Thus the concept of literacy has become more expensive and differentiated in terms of technological revolutions. Thus the main theme of the paper is just to bring innovative changes in the form of transforming the conventional or traditional classroom techniques into modern, innovative and instructive classrooms. According to the researcher, the purposes to fulfill the criteria of technology for tomorrow's classroom are:

- Digitalization: To make the whole educational process as a digitalized one.

- Globalization: To expand and expose our horizons in terms of knowledge as a source common platform for whole. 
Machine Learning and Applications: An International Journal (MLAIJ) Vol.3, No.1, March 2016

- Up-to-date knowledge: To provide a vision towards flexible, interactive and up-todate smart tools, technology and strategies.

- Student-based value education: To promote democratic conducive environment for healthy classroom interactions.

\section{REVIEW OF RELATED LITERATURE}

The researcher empirically studies many studies related to futuristic studies such as studies with multiple learning styles using technology, studies on futurology, innovations, ICT-CAI, computer-internet multimedia, E-Learning, B-Learning, M-Learning, innovative gadgets and devices etc. that have been discussed below with reference to conceptual and methodological framework.

Hiwlett-Packard (2008 A.D.) has started marketing halo conference room which allows virtual space to feel like "being there". The researchers are going on for the active learning education using virtual classroom, The University of Minnesota (2008 A.D.).

William "Bill" Lager (2010 A,D,) Lager has found electronic classroom of tomorrow (ECOT) in United States. Actually ECOT is not a home schooling-program. However, it is a public community school. Yokohama international school in Japan is designing the classroom of future. Kim Confio et.al., (2010 A.D.) has prepared a list for standardized classroom. It included flexible classroom space e.g. folding wall, blending rooms together, etc. Flexible desk/table space- table and chairs that can be easily moved and re-arranged. Different furnitures for different divisions. The flexible projection on the classroom walls using flexible speakers, Interactive whiteboard provided with the ability to adjust lightning, shelves for book etc.

Home Minister P.Chidambaram, "We are 30 years behind in technology when compared to the developed countries. This will affect the growth of the nation. Let us strive for creating high-tech classrooms to make our children have global outlook." Thus, incorporation of technology and innovation must be incorporated in today's educational system like teaching, learning, research, $\mathrm{R}$ $\&$ D research projects etc.

\subsection{Conceptual Overview}

"The study included various variables based on the components of multiple intelligence-verballinguistic, logical-mathematical, visual-spatial, bodily-kinesthetic, inter/intra-personal, naturalistic intelligence and self-efficacy teaching competencies for technology-based education process." This has been found in research of Anisha, Gopalakrishnan. V. (2014). Jeremy. V. Emst and Aaron C. Clark, 2009, conducted research on the few studies related to technological, technical and visual literacy through virtual and physical modeling among students at national level. W. Kotrlik., Donna, H. Redmann, and Joe (2009) studied on the various variable such as adoption of technology-based education among secondary teachers, their educational level, streams, and type of institutions etc. The instructional technologies included in the study such as GPS (Global Positioning System), PDA (Personal digital assistant), CD or DVD recorder, e-mail, videocassette, digital video camera, technology accommodation, video-gaming or simulation devices, as independent variable while educational qualifications/degrees as independent variables. 
Researchers like Prabha, S., and Chiniwar. (2013)., Rani, Sushma.(2013), Biswal, Ashutosh and Patel, Jayesh. S. (2009) have used independent variables as CAI and conventional method of teaching English grammar and dependent variable as attitude towards English grammar and achievement in English grammar. Abbott. (2012) used as ICT instructional method as independent variable, awareness towards ICT (internet, multimedia, CDROM, EDUSAT) as dependent variable, and the variables such as sex, age, qualification, types of working schools were considered as the personal variables. Kaius Thiel. et.al. (2014) studied on technical and theoritical aspects of eedu element game devleopment programe, the goal of which is just to inroduce eedu elements into elementary/primary school stduents. A comparasion of (Xiangyu Wang, Peter E.D. Love, Robert Klinc, Mi Jeong Kim and Peter Rex Davis.2012) were to determine whether a difference existed in the learning styles of Deakin and Chinese universities students using web 2.0 learning such as e-learning, web 2.0 learning, conventional learning as independent variables and attitudes towards various learning styles were dependent variables. Some of studies were based on the university pedagogical model to reconceptualize, with a shift in traditional university model toward innovation cooperation. Ramon, Tirado. Morueta., Jose, Ignacio. Aguaded, Gomez., and Angel, Hernando. Gomez. (2012) revealed that relationship between various variables related to institutional support measures, digital resources, satisfaction, teacher's perceived competences using e-learning model and factor analysis at university level.

Ahmad, Abu-Al-Aish., and Steve, Love. (2010); Chung, Kuo. (2007) have investigated a study to determine whether a difference existed in the mobile phone learning styles among highperformance expectancy students and low performance expectancy students of Brunel University through M-learning and e-learning in order to see the relationship between various variables such as M-learning method of teaching as independent variables; and attitudes, performance level (high-performance expectancy students and low performance expectancy students towards Mlearning system) as dependent variables in higher education context through proposed model. Mohanasundaram, K. \& Jebaraj, P. Gershom (2007) have conducted research study on integrating mobile technology in teaching-learning process. Colin, Lemmon. et.al. (2014), conducted research on the 3D virtual world for understanding student's knowledge about the scientific methods. Margaret Horna. et.al. (2007) also conducated research on 3D modelling and VR vitrtual reality uisng other variables such as BIM ( Building Information Modeling), VR virtual reality modules of teaching-learning, academic experiences, institution etc. Analysis of the experiments done on library e-resources achieved greater gains in terms of accessing to ejournals, periodicals, online renewals of books, OPAC/Web, PAC, e- resource retrievals, book bank facilities in order to improve its performance. Mukesh, Saikia. And Anjan, Gohain. (2013). The fig. no.-1, showing the studies done in different respective area related to futuristic research approach in various domains of education including case studies, small group try out, organizational and educational studies, geographical studies etc. 
Machine Learning and Applications: An International Journal (MLAIJ) Vol.3, No.1, March 2016

Fig No.-1: The Futuristic studies undertaken for empirical study
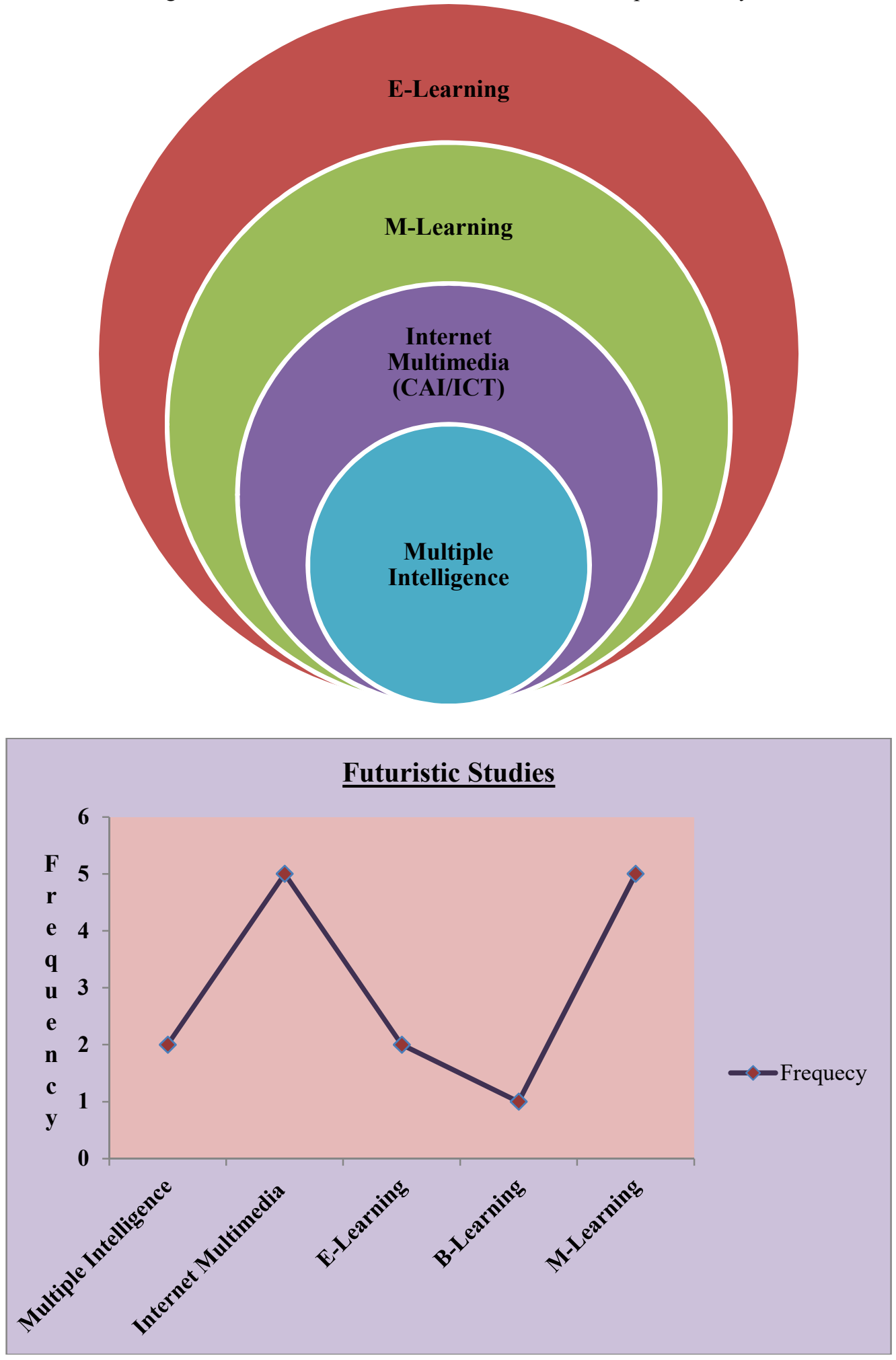
Fig. No.-2: Variations related to Futuristic studies in different domains.

The Fig. 2 shows that graphical representation of futuristic studies as empirically by the researcher. The studies related to the use of internet multimedia and mobile-learning are in high demands, e-learning and multiple-intelligence related studies are in good demands, whereas the studies related to collaborative B-learning is comparative less in number as compared to other researches done in different fields.

Fig. No.-2: Futuristic studies reference to conceptual over view

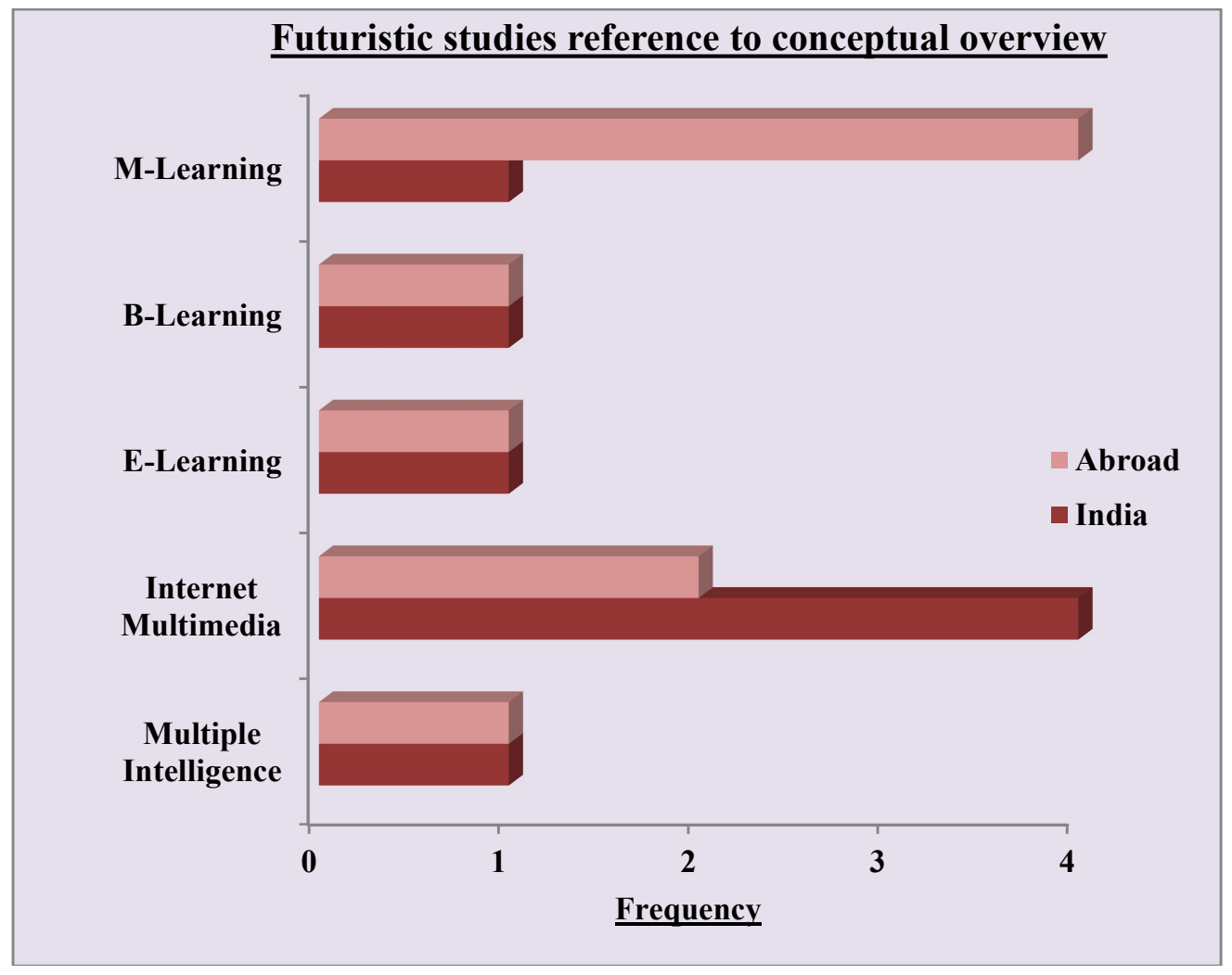

From the Fig. No. - 2, the researches done in the field on mobile-learning is highest in abroad as compared to Indian researches in M-Learning. The internet-multimedia based researches with reference to Indian context are high in numbers as compared to western studies. In rest of the research fields such as B-Learning, E-Learning, and multiple-intelligence the studies done almost equally.

\section{CONCLUSIONS}

Eventually this study exposes the latest technology and futuristic trends in various domains of education. In today's classroom practices the emphasis must be on technological basedcurriculum. Thus emphasis must be put on Information and Communication Technology (ICT) as a subject to bring about futuristic awareness towards ICT included in the present situation. It is not just providing awareness towards futuristic trends but modern tools, techniques and 
equipment must be linked educational environment. Thus in this manner we can become easily as part of globalized world. Infact there are some challenges regarding technology inculcation. Thus all of us together schools, colleges, educational institutions, and organizations should try to bring latest electronic technology into curriculum.

\section{REFERENCES}

[1] Achterman, D. (2006) Making connections with blogs and wikis. California School Library Association Jiurnal, 30(1), 29-31.

[2] Chong, E.K.M. (2008). Hrnessing distributed musical expertise through edublogging. Australian Journal of Educational Technology, 24(2), 181-194.

[3] Farmer, B., Yue, A. \&Brooks, C. (2008). Using blogging for higher order learning in large cohort university teaching: A case study. Australian Journal of Educational Technology, 24(2), 123-136.

[4] Stafan Lindell, Students as e-Citizens- Deriving future Needs of e-Services for Students, international Workshop on E-Services in Public Adminstration (WESPS2006), 31 October, University College of Boras, Sweden.

[5] MKCL: www.mkcl.org

[6] Govt. of Maharashtra : www.maharashtra.bov.in

[7] UNESCO: www.unesco.org. 